\title{
Öğrencilerin Fen Bilimleri Dersi Sınıf Etkinlikleri Algı ve Fen Konularına Yönelik İlgi Düzeylerinin
}

\section{Bazı Değişkenler Açısından İncelenmesi}

\author{
Murat Özarslan
}

Milli Ĕ̆itim Bakanlı̆̆l, Kocaeli, Türkiye

Sorumlu Yazar: Murat Özarslan, muratozarslan14@gmail.com

Makale Türü: Araştırma Makalesi

Kaynak Gösterimi: Özarslan, M. (2019). Öğrencilerin fen bilimleri dersi sınıf etkinlikleri algı ve fen konularına yönelik ilgi düzeylerinin bazı değişkenler açısından incelenmesi. Eğitimde Kuram ve Uygulama, 15(3), 204-219. doi: 10.17244/eku.536638

\section{Examination of Students' Perception of Science Classroom Activities and Their Interest in Science}

\author{
Subjects in Terms of Some Variables \\ Murat Özarslan \\ Ministry of National Education, Kocaeli, Turkey
}

Corresponding Author: Murat Özarslan, muratozarslan14@gmail.com

Article Type: Research Article

To Cite This Article: Özarslan, M. (2019). Öğrencilerin fen bilimleri dersi sınıf etkinlikleri algı ve fen konularına yönelik ilgi düzeylerinin bazı değişkenler açısından incelenmesi. Eğitimde Kuram ve Uygulama, 15(3), 204-219. doi: 10.17244/eku.536638 
2019, 15(3), 204-219

\title{
Öğrencilerin Fen Bilimleri Dersi Sınıf Etkinlikleri Algı ve Fen Konularına Yönelik İlgi Düzeylerinin Bazı Değişkenler Açısından İncelenmesi
}

\author{
Murat Özarslan
}

Milli Ĕ̌itim Bakanlı̆̆l, Kocaeli, Türkiye

ORCID: http://orcid.org/0000-0003-2129-4347

\begin{tabular}{|c|c|}
\hline$\ddot{\mathbf{O z} z}$ & Makale Bilgisi \\
\hline $\begin{array}{l}\text { Çalışmada öğrencilerin fen bilimleri dersi sınıf etkinliklerine ilişkin algıları ile fen } \\
\text { konularına yönelik ilgi düzeylerinin cinsiyet ve sınıf değişkenleri açısından belirlenmesi } \\
\text { ve aralarındaki ilişkinin ortaya konulması amaçlanmıştır. Çalışma 2018-2019 akademik } \\
\text { yılı bahar döneminde Marmara bölgesinin } 2 \text { farklı ilinden } 2 \text { okulda toplam (183 kız, } 204 \\
\text { erkek) } 387 \text { öğrenci ile gerçekleştirilmiştir. Çalışmaya 6-8. sınıf öğrencileri dahil } \\
\text { edilmiştir. Çalışma grubunu belirlenmesinde kolay ulaşılabilir durum örneklemesi } \\
\text { yöntemi kullanılmıştır. Çalışma da tarama yöntemlerinden kesitsel tarama yöntemi } \\
\text { kullanılmıştır. Veriler, Fen Konularına Yönelik İlgi Ölçeği ve Fen Bilimleri Dersi Sinıf } \\
\text { Etkinliklerim Ölçeği ile elde edilmiştir. Verilerin analizinde betimsel istatistik, tek yönlü } \\
\text { varyans (ANOVA), bağımsız gruplar t-Testi ve korelasyon analizi yöntemleri } \\
\text { uygulanmıştır. Araştırma sonuçlarında öğrencilerin fen bilimleri etkinliklerine ilişkin zevk } \\
\text { alma, ilgi duyma, seçim yapabilme ve sınırları zorlama algı ve fen konularına yönelik ilgi } \\
\text { düzeylerinin orta düzeyde olduğu belirlenmiştir. Araştırmada, kız öğrencilerin fen } \\
\text { konularına yönelik ilgilerinin erkeklerden daha fazla olduğu ancak sınıf düzeyine göre } \\
\text { öğrencilerinin fen konularına yönelik ilgilerinin istatiksel olarak anlamlı şekilde } \\
\text { farklılaşmadığı belirlenmiştir. Ayrıca cinsiyet ve sınıf düzeyine göre öğrencilerin fen } \\
\text { bilimleri dersi sınıf etkinliklerine yönelik algıları arasında anlamlı bir farklılık olmadığı da } \\
\text { tespit edilmiştir. Öğrencilerin fen bilimleri dersi sınıf etkinliklerine yönelik algı puanları } \\
\text { ile fen konularına yönelik ilgi puanları arasında pozitif yönde istatistiksel olarak anlamlı } \\
\text { zayıf düzeyde bir ilişki tespit edilmiştir. }\end{array}$ & $\begin{array}{l}\text { Makale Geçmişi: } \\
\text { Geliş: } 17 \text { Mayıs } 2019 \\
\text { Düzeltme: 09 Eylül } 2019 \\
\text { Kabul: } 10 \text { Eylül } 2019 \\
\text { Makale Türü: Araştırma } \\
\text { Makalesi }\end{array}$ \\
\hline
\end{tabular}




\section{Examination of Students' Perception of Science Classroom Activities and Their Interest in Science}

\section{Subjects in Terms of Some Variables}

\begin{tabular}{|c|c|}
\hline Abstract & Article Info \\
\hline $\begin{array}{l}\text { The aim of the study was to determine the students' perceptions about science classroom } \\
\text { activities and their interest in science subjects in terms of gender and class variables and to } \\
\text { identify the relationship between them. It was carried out with } 387 \text { students ( } 183 \text { females, } \\
204 \text { males) from } 2 \text { schools in } 2 \text { different provinces of Marmara region and during the } \\
\text { spring term of } 2018-2019 \text { academic year. The study was participated in by 6th to8th grade } \\
\text { students. The convenience sampling method was used to determine the study group. A } \\
\text { cross-sectional screening method was used in the study. The data were collected by using } \\
\text { the Science Classroom Activities Scale and Science Subjects Interest Scale. Descriptive } \\
\text { statistics, one-way variance (ANOVA), independent groups t-test and correlation analysis } \\
\text { were used to analyse the data. According to the results of the research, it was determined } \\
\text { that the interest levels of students in the science courses and their perceptions of pushing } \\
\text { the limits, making a selection, and showing interest in the activities of science courses } \\
\text { were at a moderate level. It was determined that female students had more interest in } \\
\text { science than males; however, it was also found that, according to the grade level, the } \\
\text { interest levels of students concerning the science subjects did not differ statistically } \\
\text { significantly. It was also determined that there was statistically no significant difference } \\
\text { between the perceptions of students concerning science activities according to gender and } \\
\text { grade level. A positive, statistically significant, and weak correlation was found between } \\
\text { the students' perception scores for the science class activities and the interest scores for } \\
\text { science subjects. }\end{array}$ & $\begin{array}{l}\text { Keywords: Individual } \\
\text { differences, interest, } \\
\text { perception, science classroom } \\
\text { activities, science learning } \\
\text { Article History: } \\
\text { Received: } 17 \text { May } 2019 \\
\text { Revised: } 09 \text { September } 2019 \\
\text { Accepted: } 10 \text { September } 2019 \\
\text { Article Type: Research Article }\end{array}$ \\
\hline
\end{tabular}




\section{Giriş}

Günümüz Fen Bilimleri Dersi Öğretim Programlarında öğrencilerin bireysel özellikleri ve farklılıklarını dikkate alan öğrenme kuram ve yaklaşımları benimsenmiştir (MEB, 2013). Bu programlar öğrenci merkezli öğretim yaklaşımına dayandırılmaktadır. Bu noktada öğrencilerin bilgilerle doğrudan etkileşimde bulunmalarını, yaparak ve yaşayarak öğrenmelerini sağlamak için öğrenme-öğretme sürecinin merkezinde eğitsel etkinlikler yer almaktadır (Doyle, 1983). $\mathrm{Bu}$ doğrultuda eğitimcilerin öğrencilerle birlikte eğitsel etkinlikler yapması gerekmektedir (MEB, 2013).

Sinıflar, öğrenme ve öğretme etkinliklerinin uygulandığı ortamlardır (Gülbahar ve Aksungur, 2018). Sinıf ortamlarında yapılan etkinlikler yaparak yaşayarak öğrenmeyi kolaylaştırma ve iletişim becerilerini geliştirme noktasında önemli görülmektedir. Sınıf etkinlikleri öğrencinin ön bilgilerini aktive etmeli, yeni bilgileri ile beraber ön bilgilerini yapılandırmalıdır (Açıkgöz, 2002). Öğrenme etkinlikleri, öğrencileri öğrenmeye motive etmeli ve ilgilerini konuya çekmelidir (Adıgüzel, 2009). Diğer taraftan sınıf etkinliklerinde öğretmen öğrencilere anında geri bildirim vermekte, öğrencilerin ilgisini ve coşkusunu geliştirmektedir (Moore, 2011). Bu nedenle, fen bilimleri dersi sınıf etkinliklerinin uygun şekilde tasarlanması ve uygulanması gerekmektedir.

Sınıf etkinliklerini öğrencilerin nasıl algıladıkları önemlidir. Çünkü fen bilimleri dersi sınıf etkinlikleri hakkındaki öğrenci algısı fen öğretim ve müfredat uygulamaları hakkında eğitimci ve araştırmacılara bilgi sağlayabilir. Bu bilgiler öğrencilerin okul ortamı, fen öğretiminin geliştirilmesi ve başarısızlık probleminin önlenmesinde fayda sağlamaktadır (Deniz ve Saranl1, 2017; Gentry, Gable ve Rizza , 2002; Kiwanuka vd., 2016; Matthews ve McBee, 2007). Ayrıca öğrenci algısı konusundaki çalışmalar, öğrenme ortamının değerlendirmesi ve öğrenme ortamının akademik başarı üzerine etkisi noktasına odaklanmıştır (Ames ve Archer, 1988; Church, Elliot ve Gable, 2001). Church vd., (2001), sınıf ortamı ile akademik başarı arasında dolaylı bir ilişkinin varlığını ortaya koymuşlardır. Özetle sınıf ortamının öğrencilerin olumlu algı geliştirecekleri şekilde düzenlenmesi öğrenci başarısını olumlu geliştirilebilir.

Fen bilimleri dersi sınıf etkinliklerine yönelik öğrencilerin olumlu algılarının geliştirilmesi ve başarılarının arıtılması için etkinliklere yönelik ilgi, yapılacak olan etkinliklerin sınırlarını zorlama, etkinlikler hakkında seçeneklerin olması ve etkinlik konularından zevk alma gibi etkenler öğrenme ortamının kalitesini artıran etkenlerdir. Bu etkenler öğrenci motivasyonunu ve başarısını desteklemektedir (Gentry vd., 2002; Yang, Gentry ve Choi, 2012). Bunlara ek olarak öğrendiklerimiz, düşündüklerimiz ve etkinlikler beyin hücrelerimizde yeni bağlantılar ve değişimler oluşturmaktadır. Beyin hücrelerimiz ve oluşan bağlantılar en fazla ilgi çekici, sınırları zorlayıcı ve zevk verici öğrenmeler ve uygulamalar tarafindan uyarılmaktadır (Clark, 2015).

Fen bilimleri dersi sınıf etkinliklerinin tasarlanmasında öğrenci ilgisi ve zorlayıcıların önemli olduğu belirtilmiştir (Ravenna, 2008). Alanyazında, fen bilimleri öğretmenlerinin öğrencilerin ilgi ve meraklarını dikkate alarak ders içi etkinlikler düzenlemeleri durumunda öğrencilerin derse yönelik motivasyonunun artacağı belirtilmiştir (Emre, 2012; Emre ve Erten, 2012). Clifford (1990) öğrencilerin sınırlarını zorlayıcı uygulamaların öğrenci motivasyonu ve başarıyı geliştireceğini belirtmiştir. Hootstein (1994), öğrencileri motive etmek için öğrenmenin; öğrencilerin ilgi, ihtiyaç, endişe ve tecrübeleri ile ilişkilendirilmesini önermektedir. Ngoi ve Vondracek (2004) bağımsız çalışmalar, araştırma projeleri ve program dışı akademik rekabet içeren çalışmaların öğrencileri hem zorladığını hem de motive ettiğini ortaya koymuştur.

Fen bilimleri dersi sınıf etkinliklerinin tasarlanmasında diğer önemli bir etmen ise etkinliklerde öğrencilere tercih yapabilme imkânının verilmesidir (Deniz ve Saranl1, 2017). Öğrencilere fen bilimleri dersi etkinliklerinde tercih yapabilme imkânı verilmesi onların fen dersine ve konularına yönelik öğrenmelerini, ilgilerini ve başarısını artırmaktadır (Deniz ve Saranlı, 2017; Pintrich ve De Grot, 1990). Sınıf etkinliklerinde öğrencilere tercih hakk1 verilmesi öğrencilerin uğraşlardan zevk almasını, potansiyellerini keşfetmesini ve geliştirilmesini sağlayacaktır (Bruning, Schraw ve Norby, 2014; Deci, 1995; Glasser, 1996; Kök, 2012; Özarslan ve Çetin, 2018; Sak, 2012). Eğitsel etkinliklerden zevk alınması da öğrencileri öğrenme sürecinde motive edici diğer bir faktördür. Günlük sınıf etkinliklerinden zevk alınmasını sağlayacak unsurlara dikkat edildiğinde okulun ve sınıfların daha iyi bir öğrenme ortamı haline dönüşmesi mümkündür (Deniz ve Saranl1, 2017). Renzulli (1994), en iyi öğrenmenin çocukların yaptıklarından keyif aldıkları zaman gerçekleştiğini belirtmiştir.

Öğrencilerin fen bilimleri dersi sınıf etkinlikleri algısının önemli olduğu ve bu algıyı etkileyen ilgi, sınırları zorlama, tercih imkânı ve zevk alma gibi değişkenler temelinde alanyazın incelendiğinde, bu konularda yeterli düzeyde araştırmaya ulaşılamamıştır. Sınırlı sayıdaki araştırmalarda ise, ortaokul öğrencilerinin ilköğretim 
öğrencilerine göre sınıf etkinliklerinde daha az seçim yapabildiği, etkinlikleri daha az ilgi çekici ve eğlenceli bulduğu tespit edilmiştir. 3.-8. sınıfa doğru öğrencilerin fen bilimleri dersi etkinliklerine yönelik algılarının sınıf seviyesi arttıkça azaldığı belirlenmiştir. Kızların sınıf etkinliklerini erkeklerden daha ilginç ve zevkli olarak algıladıkları tespit edilmiştir (Gentry vd., 2002). Fen bilimleri dersi sınıf etkinlikleri noktasında önemli olduğu düşünülen diğer bir değişkende öğrencilerin fen konularına yönelik ilgisidir.

İlgi, belli bir olaya, nesneye veya düşünceye duyulan eğilim, merak, hoşlanma ve onlarla meşgul olmak demektir (Erten, 2008; Krapp, Hidi ve Renninger, 1992). İlgi, eğitim alanındaki araştırmacılar tarafından önemli görülen bireysel farkl11ıklardan biridir. Weber, Martin ve Patterson (2010) öğrencinin derse ilgisinin akademik başarının önemli bir açıklayıcısı olduğunu belirtmişlerdir. Lin, Hong ve Chen (2013), Mazer (2013) ile Hidi (2000) öğrencilerin konulara ilgisinin artması ile fen dersine katılımının ve öğrenme motivasyonunun arttı̆̆ını ifade etmişlerdir. Ancak öğrencilerin öğrenilen konuya ilgisinin azalması dikkat dağınıklığı ve motivasyon düşüklügüne neden olmaktadır (Hidi ve Harackiewicz, 2000; Kopp, Mills ve D'Mello, 2016; Rotgans ve Schmidt, 2017). Bu noktada, öğrencilerin fen konularına yönelik ilgisinin olumlu yönde nasıl geliştirilebileceği önemli görülmektedir.

İlgi, çevresel özelliklerde meydana gelecek düzenlemelerle kontrol edilebilecek bir değişkendir (Schraw, Flowerday ve Lehman, 2001). Öğrencilerin derse ve konulara ilgisi öğretmen, konunun içeriği, yöntem, sınıf atmosferi gibi pek çok faktörle ilişkilidir (Yaman, 2009). Eğitimciler tarafından bireye verilen sınıf etkinliklerinin tasarımı ve öğretme stratejilerinde yapılacak değişimlerle, ilgi olumlu yönde geliştirilebilmektedir (Kang, Scharmann, Kang ve Noh, 2010). Erten (2008) öğrencilerin sınıf etkinliklerinde gerçek nesnelerle yakın ilişki içerisinde çalışmalarının öğrencilerin konuya yönelik ilgisini artıracağını ve onları meraklandıracağını belirtmiştir. Ayrıca öğretim sürecinde sunulan metinlerin ve konu içeriklerinin düzenlenmesi, ilgi çekici materyallerin sunulması, problem tabanlı öğrenme gibi çeşitli uygulamalar öğrencilerin ilgi düzeylerini arttırabilmektedir (Knogler, Harackiewicz, Gegenfurtner ve Lewalter, 2015; Schraw vd., 2001).

Alanyazında fen konularına yönelik ilgi noktasında yapılan çalışmalarda, ülkemizde öğrencilerin fen konularına yönelik ilgi düzeylerinin yüksek olduğu belirlenmiştir (Eke, 2010). Eder (1992) çalışmasında, 4. ve 5. sınıf öğrencilerinin fen dersinden çok keyif aldıklarını, sınıfa büyük bir merak ve öğrenme isteği ile geldikleri ortaya koymuştur. Erten (2008), 6-10. sınıf öğrencilerinin insan vücudu, organları ve insan beslenmesi ve sağlığına yönelik konulara ilgilerinin yüksek olduğunu ortaya koymuştur. Öğrencilerin ilgilerinin 6. sınıftan 9. sınıf düzeyine doğru gittikçe azaldığını belirlenmiştir. Çepni, Küçük ve Ayvacı (2006) 4. sınıf öğrencilerinin, dünya ve gezegenler ve uzay gibi konulara ilgilerinin yüksek olduğunu tespit etmiştir. Lâçin Şimşek (2007) öğrencilerin biyoloji konularına, teknoloji, kimya ve astronomiye yönelik ilgilerinin yüksek olduğunu ifade etmiştir.

Alanyazında, öğrencilerin hangi fen konularına ne düzeyde ilgi duyduğunu ortaya koyan çalışmalarla beraber kız ve erkek öğrencilerin fen konularına yönelik ilgileri arasındaki farklılıkların araştırıldığı birçok çalışmada yer almaktadır. Örneğin; Smail ve Kelly (1984), Löwe (1992), Erten (2008), Gehlhaar, Klepel, Fankhänel (1999) ile Dervişoğlu, Yaman ve Soran (2004) kız öğrencilerin genel biyoloji, fizik, doğa ve insan fizyoloji konularına yönelik ilgilerinin erkek öğrencilerden daha fazla olduğunu tespit etmişlerdir. Finke (1998), 5. sınıftan 11. sınıfa kadar öğrencilerin fizyoloji, biyoloji ve çevre konularına yönelik ilgilerinin sınıf seviyesi arttıkça azaldığını, kız öğrencilerin bu konulara yönelik ilgilerinin erkeklerden daha fazla olduğu belirtmiştir. Gilbert (2006) ile Osbourn ve Collins (2000), öğrencilerin küçük sınıflarda fen konularına daha fazla ilgi gösterdiklerini ve sınıf seviyesi arttıkça ilginin azaldığını belirtmişlerdir. Diğer çalışmalarda ise öğrencilerin ilgi alanlarının ergenlikle beraber azaldığ 1 ortaya konulmuştur (Finke, 1998). Yıldırım ve Köklükaya (2016) ile Berube (2000) erkek öğrencilerin fen konularına yönelik ilgi düzeylerinin kız öğrencilerden daha fazla olduğunu ortaya koymuşlardır. Holstermann ve Bögeholz (2007) erkek öğrencilerin tehlikeli uygulamalara, fiziğe ve teknolojiye kız öğrencilerden daha fazla ilgi duyduğunu belirlemişlerdir.

Öğrencilerin fen bilimleri dersi sınıf etkinlikleri algısı ve fen konularına ilgisi ile bu değişkenler arasındaki ilişkinin belirlenmesi önemlidir. Çünkü fen bilimleri dersi sınıf etkinliklerinin öğrencilerde konulara yönelik merak, şaşkınlık ve heyecan yaratması gerekmektedir (Schiefele ve Köller, 2001). Bu noktada sınıf etkinliklerine olan ilgi, yapılacak olan etkinliklerin sınırlarını zorlama, etkinliklerde seçeneklerin olması ve etkinlik konularından zevk alma gibi etkenlerin fen bilimleri sınıf etkinliklerinde öğrenciler tarafından hangi düzeyde algılandığı ve öğrencilerin 
ilgilerine etkisinin belirlenmesi gerekmektedir. Ayrıca Hoffmann (2002) öğrenme öğretme ortamlarında ilginin araştırılmasını önermektedir. Ancak alanyazında, bu çalışmanın amacı ile ilişkili araştırmaların yeterli düzeyde olmadığı görülmektedir. Bu noktada araştırma sonucunun alanyazına katkı sağlayacağı düşünülmektedir. Bu sayede öğrencilerin fen konularına ilgilerini daha fazla artıracak ve meraklandıracak dolaylı olarak ta fen konularına yönelik motivasyonu ve başarıyı destekleyecek daha nitelikli fen bilimleri dersi sınıf etkinlikleri geliştirilebilir.

Çalışmada öğrencilerin fen bilimleri dersi sınıf etkinliklerine ilişkin algıları ile fen konularına yönelik ilgi düzeylerinin cinsiyet ve sınıf değişkenleri açısından belirlenmesi ve aralarındaki ilişkinin ortaya konulması amaçlanmıştır. Bu doğrultuda belirlenen alt problemler şunlardır:

1. Cinsiyet değişkenine göre öğrencilerin fen bilimleri dersi sınıf etkinliklerine yönelik algı ve fen konularına yönelik ilgi puanları arasında anlamlı bir farklılık var mıdır?

2. Sınıf düzeyi değişkenine göre öğrencilerin fen bilimleri dersi sınıf etkinliklerine yönelik algı ve fen konularına yönelik ilgi puanları arasında anlamlı bir farklılık var mıdır?

3. Öğrencilerin fen bilimleri dersi sınıf etkinliklerine yönelik algı puanları ile fen konularına yönelik ilgi puanları arasında anlamlı bir ilişki var mıdır?

\section{Yöntem}

Çalışmada tarama yöntemlerinden kesitsel tarama yöntemi kullanılmıştır. Tarama yöntemi bir grubun belirli özelliklerini belirlemek için verilerin toplanmasını amaçlamaktadır (Büyüköztürk, Çakmak, Akgün, Karadeniz ve Demirel, 2012). Kesitsel tarama yöntemi, geniş grupları içeren durumlar için evrenin içerisinden bir örneklem grubu belirlenerek verilerin toplanması şeklindedir (Aypay vd., 2010).

\section{Çalışma Grubu}

Çalışma grubu 2018-2019 akademik yılı bahar döneminde, Marmara bölgesinin 2 farklı ilinden 2 farklı okulda, toplam 387 ortaokul öğrencisi ile gerçekleştirilmiştir. Çalışma grubu, kolay ulaşılabilir durum örneklemesi yöntemi ile belirlenmiştir (Büyüköztürk vd., 2011). Çalışmaya 6-8. sınıf öğrencileri dahil edilmiştir. Öğrencilerin çalışmaya katılımında gönüllük esası dikkate alınmıştır. Ayrıca ilgili kurumlardan gerekli izinler alınmıştır. Katılımcılara ait bilgiler cinsiyet ve sınıf düzeyi değişkenine göre Tablo 1'de sunulmuştur.

Tablo 1. Öğrencilerin Okul ve Sınıflarına göre Betimsel İstatistik Bilgileri

\begin{tabular}{llccc}
\hline \multirow{2}{*}{ Değişkenler } & & Okul I & Okul II & \multirow{2}{*}{ Toplam } \\
\cline { 3 - 4 } Cinsiyet & Kiz & $\mathbf{N}$ & $\mathbf{N}$ & \\
\hline \multirow{2}{*}{ Sinıf düzeyi } & Erkek & 100 & 83 & 183 \\
& 6. sinıf & 104 & 100 & 204 \\
\hline & 7. sinıf & 63 & 60 & 123 \\
& 8. sinıf & 70 & 66 & 136 \\
& Toplam & 204 & 57 & 128 \\
\hline
\end{tabular}

\section{Veri Toplama Araçları}

Araştırma verileri Fen Bilimleri Dersi Sınıf Etkinliklerim Ölçeği ve Fen Konularına Yönelik İlgi Ölçeği ile elde edilmiştir.

\section{Fen Bilimleri Dersi Sinıf Etkinliklerim Ölçeği:}

Ölçek, Gentry ve Gable (2001) tarafından geliştirilmiş ve Türkçeye uyarlaması Deniz ve Saranlı (2017) tarafindan yapılmıştır. Fen bilimleri dersi sınıflarındaki etkinliklere yönelik ilgi duyma, etkinlik yapılan konudan zevk alma, konuyla ilgili seçim yapabilme ve etkinlik sırasında sınırlarını zorlama boyutlarına ilişkin öğrenci algılarının ölçülmesi amacıyla bu ölçek geliştirilmiştir. Ölçek "Seçim yapabilme" (Örnek madde; Sınıfta çalışacağım araç-gereci kendim seçebilirim.), "Konudan zevk alma" (Örnek madde; Sınıftaki etkinliklerden keyif alırım.), "İlgi duyma" (Örnek madde; Sınıfta yaptığım etkinlikler ilgimi çeker.) ve "Sınırlarını zorlama" (Örnek madde; Sınıf etkinliklerimde yeni şeyler deneyerek yeteneklerimi zorlarım.)" olmak üzere 4 alt boyuttan ve 32 maddeden oluşmaktadır. Maddelerin cevap seçenekleri; "Hiçbir Zaman" (1),"Nadiren/Seyrek" (2), "Bazen” (3), "Çoğunlukla" (4) ve "Her Zaman" (5) şeklindedir. Likert tipinde hazırlanan ölçekte her alt boyut farklı olarak değerlendirilmektedir. Ölçeğin puanlarının tüm alt boyutlarda yüksek çıkması ögrencinin sınıfındaki fen bilimleri dersi sınıf etkinliklerini yüksek düzeyde ilgi çekici, zevkli/keyifli, seçim yapmaya müsait ve zihinsel olarak zorlayıcı olarak algıladığı anlamına gelmektedir. 
Ölçeğin tamamlaması için öğrencilere 15 dakikada süre verilmiştir. Bu çalışmada ölçeğin Cronbach Alfa güvenirlik katsayısı ise .926 olarak belirlenmiştir.

Fen Konularına Yönelik İlgi Ölçeği:

Ölçek, öğrencilerin fen konularına yönelik ilgi düzeylerini belirlemek amacıyla geliştirilmiştir. Harty ve Beall (1984) tarafindan geliştirilmiş olan 'İlgi Ölçeği' (Children's Science Curiosity Measure) temel alınarak Laçin Şimşek ve Nuhoğlu (2009) tarafından geliştirilmiş, geçerlilik ve güvenirlik analizleri yapılmıştır. Ölçeğin, Cronbach Alpha güvenirlik katsayısı $\alpha=.79$ olarak tespit edilmiştir. Ölçek, 5'li likert tipinde olup "Tamamen katılıyorum", "Katılıyorum" "Kararsızım" "Katılmıyorum" ve "Tamamen katılmıyorum" şeklinde 27 maddeden oluşmaktadır. Bu maddeler sebep sonuç ilişkileri ile "Keşfetme, doğayı inceleme, gözlem yapma, fen konularını günlük hayatla ilişkilendirme, fen konularını kitle iletişim araçları yardımıyla takip etme ve bireysel ilgi” olmak üzere 6 alt boyutta gruplandırılmıştır. Ölçekten alınabilecek en düşük puan 0 en yüksek puan ise 108'dir. Bu çalışmada ise ölçeğin Cronbach Alpha güvenirlik katsayısı $\alpha=.867$ olarak bulunmuştur.

\section{Veri Analizi}

Çalışmada, Fen Bilimleri Dersi Sınıf Etkinliklerim Ölçeği ile Fen Konularına Yönelik İlgi Ölçeği verilerinin normal dağılım gösterip göstermediğine karar vermek için çarpıklık (kurtosis) ve basıklık (skewness) değerleri dikkate alınmıştır (George ve Mallery, 2010). Puanların çarpıklık ve basıklık değerlerinin +1 ile -1 arasında değişim gösterdiği belirlenmiş ve verilerin normal dağılım gösterdiğine karar verilmiştir (Büyüköztürk vd., 2011). Öğrencilerin fen bilimleri dersi sınıf etkinliklerine yönelik algı ve fen konularına yönelik ilgi puanlarının cinsiyete ve sınıf düzeyleri göre istatistiksel olarak anlamlı farklılık gösterip göstermediğini belirlemek için sırası ile betimsel istatistik, bağımsız gruplar t-testi ve tek yönlü varyans (ANOVA) analizleri yapılmıştır. Öğrencilerin fen bilimleri dersi sınıf etkinliklerine yönelik algı puanları ile fen konularına yönelik ilgi puanları arasındaki ilişkinin belirlenmesi amacıyla korelasyon analizi uygulanmıştır.

\section{Bulgular}

Bu bölümde öğrencilerin Fen Bilimleri Dersi Sınıf Etkinliklerim Ölçeği ve Fen Konularına Yönelik İlgi Ölçeği’nden elde edilen verilerin analiz sonuçları sunulmuştur. Ölçeklerden elde edilen puanların betimsel istatistik ve merkezi eğilim sonuçları Tablo 2'de verilmiştir.

Tablo 2. Ölçeklere ait Betimsel İstatistik ve Merkezi Eğilim Ölçü Sonuçları

\begin{tabular}{llccccc}
\hline Ölçek & Alt Boyutlar & $\mathbf{N}$ & $\overline{\mathbf{X}}$ & $\mathbf{S s}$ & Basıklık & Çarpıklık \\
\hline \multirow{2}{*}{ Fen Bilimleri Dersi Sınıf } & İlgi Duyma & 387 & 3.50 & .746 & -.191 & -.246 \\
Etkinliklerim Ölçeği & Sinırlarını Zorlama & 387 & 3.49 & .715 & -.094 & -.390 \\
& Seçim Yapabilme & 387 & 3.63 & .783 & -.129 & -.628 \\
\hline Fen Konularına Yönelik İlgi Ölçeği & Konudan Zevk Alma & 387 & 3.74 & .828 & -.518 & -.036 \\
\hline
\end{tabular}

Tablo 2'ye göre, Fen Bilimleri Dersi Sınıf Etkinliklerim Ölçeği alt boyutlarında öğrencilerin etkinlik yapılan konudan zevk alma puan ortalamasının en yüksek $(\overline{\mathrm{X}}=3.74)$, etkinlik sırasında sınırlarını zorlama ve ilgi duyma puan ortalamasının ise en düşük seviyede $(\bar{X}=3.49 ; \bar{X}=3.50)$ olduğu belirlenmiştir. Ayrıca fen konularına yönelik ilgi puanların ortalamasının ise $\bar{X}=3.62$ olduğu görülmüştür. Bu sonuçlara göre öğrencilerin fen bilimleri dersi sınıf etkinlikleri algı düzeylerinin ve fen konularına yönelik ilgilerinin orta düzeyde olduğu söylenilebilir.

Cinsiyet değişkenine göre Fen Bilimleri Dersi Sınıf Etkinliklerim ve Fen Konularına Yönelik İlgi Ölçekleri bulgularına yönelik bağımsız gruplar t-Testi analiz sonuçları Tablo 3 'te sunulmuştur. 
Tablo 3. Cinsiyet Değişkenine göre Fen Bilimleri Dersi Sınıf Etkinliklerim ve Fen Konularına Yönelik İlgi Ölçekleri Bağımsız Gruplar t-Testi Analiz Sonuçları

\begin{tabular}{|c|c|c|c|c|c|c|c|}
\hline Ölçek & Alt Boyutlar & Cinsiyet & $\mathbf{N}$ & $\overline{\mathbf{X}}$ & Ss & $\mathbf{t}$ & $\mathbf{p}^{*}$ \\
\hline \multirow{8}{*}{$\begin{array}{l}\text { Fen Bilimleri Dersi Sınıf } \\
\text { Etkinliklerim } \\
\text { Ölçeği }\end{array}$} & \multirow{2}{*}{ İlgi Duyma } & $\mathrm{K} 1 \mathrm{Z}$ & 183 & 3.52 & .741 & \multirow{2}{*}{.622} & \multirow{2}{*}{0.53} \\
\hline & & Erkek & 204 & 3.48 & .752 & & \\
\hline & \multirow{2}{*}{ Sinırlarını Zorlama } & Kiz & 183 & 3.51 & .722 & \multirow{2}{*}{.712} & \multirow{2}{*}{0.47} \\
\hline & & Erkek & 204 & 3.46 & .711 & & \\
\hline & \multirow{2}{*}{ Seçim Yapabilme } & Kiz & 183 & 3.59 & .850 & \multirow{2}{*}{-1.077} & \multirow{2}{*}{0,28} \\
\hline & & Erkek & 204 & 3.67 & .718 & & \\
\hline & \multirow{2}{*}{ Konudan Zevk Alma } & Kiz & 183 & 3.76 & .885 & \multirow{2}{*}{.623} & \multirow{2}{*}{0,53} \\
\hline & & Erkek & 204 & 3.71 & .775 & & \\
\hline \multirow{2}{*}{\multicolumn{2}{|c|}{ Fen Konularına Yönelik İlgi Ölçeği }} & Kiz & 183 & 3.72 & .617 & \multirow{2}{*}{2.958} & \multirow{2}{*}{$0,00^{*}$} \\
\hline & & Erkek & 204 & 3.54 & .581 & & \\
\hline
\end{tabular}

$* \mathrm{p}<.01$

Tablo 3'e göre, Fen Bilimleri Dersi Sınıf Etkinlilerim Ölçeği alt boyut puanlarının kız ve erkek öğrenciler arasında istatistiksel olarak anlamlı farklılık göstermediği belirlenmiştir $(\mathrm{p}>.05)$. Ayrıca cinsiyete göre Fen Konularına Yönelik İlgi Ölçeği puanlarının kız öğrenciler lehine istatistiksel olarak anlamlı farklılık gösterdiği tespit edilmiştir $(\mathrm{p}<.01)$. Bu sonuçlara göre, kız öğrencilerin erkek öğrencilere göre fen konularına yönelik ilgilerinin daha yüksek olduğu ancak onların fen bilimleri dersi sınıf etkinliklerine yönelik algılarının benzer olduğu söylenilebilir. Sınıf değişkenine göre Fen Bilimleri Dersi Sınıf Etkinliklerim Algı ve Fen Konularına Yönelik İlgi Ölçekleri bulgularına yönelik tek yönlü varyans analizi sonuçları Tablo 4'te sunulmuştur.

Tablo 4. Sınıf Değişkenine göre Fen Bilimleri Dersi Sınıf Etkinliklerim ve Fen Konularına Yönelik İlgi Ölçekleri

\begin{tabular}{|c|c|c|c|c|c|c|c|}
\hline & arı Tek Yönlü AN & VA Sonuçlar & & & & & \\
\hline Ölçek & Alt Boyutlar & Sinıf Düzeyi & $\mathbf{N}$ & $\overline{\mathbf{X}}$ & Ss & $\mathbf{F}$ & $\mathbf{p}^{*}$ \\
\hline \multirow{12}{*}{$\begin{array}{l}\text { Fen Bilimleri } \\
\text { Dersi Sınıf } \\
\text { Etkinliklerim } \\
\text { Ölçeği }\end{array}$} & \multirow{3}{*}{ İlgi Duyma } & 6. sinif & 119 & 3.48 & .805 & \multirow{3}{*}{.134} & \multirow{3}{*}{.875} \\
\hline & & 7. $\sin 1 f$ & 134 & 3.48 & .748 & & \\
\hline & & 8. $\sin 1 f$ & 134 & 3.52 & .693 & & \\
\hline & \multirow{3}{*}{ Sinırlarını Zorlama } & 6. sinif & 119 & 3.41 & .763 & \multirow{3}{*}{.899} & \multirow{3}{*}{.408} \\
\hline & & 7. $\sin 1 f$ & 134 & 3.51 & .684 & & \\
\hline & & 8. $\sin 1 f$ & 134 & 3.52 & .703 & & \\
\hline & \multirow{3}{*}{ Seçim Yapabilme } & 6. $\sin 1 f$ & 119 & 3.53 & .771 & \multirow{3}{*}{1.954} & \multirow{3}{*}{143} \\
\hline & & 7. $\sin 1 f$ & 134 & 3.63 & .892 & & \\
\hline & & 8. $\sin 1 f$ & 134 & 3.72 & .664 & & \\
\hline & \multirow{3}{*}{ Konudan Zevk Alma } & 6. sinif & 119 & 3.79 & .721 & \multirow{3}{*}{2.605} & \multirow{3}{*}{.075 } \\
\hline & & 7. sinif & 134 & 3.60 & .945 & & \\
\hline & & 8. sinif & 134 & 3.82 & .781 & & \\
\hline \multirow{3}{*}{ Fen Konularına Yönelik İlgi Ölçeği } & & 6. sinif & 119 & 3.60 & .629 & \multirow{3}{*}{.270} & \multirow{3}{*}{.764} \\
\hline & & 7. $\sin 1 f$ & 134 & 3.61 & .595 & & \\
\hline & & 8. sinif & 134 & 3.65 & .594 & & \\
\hline
\end{tabular}

Tablo 4 incelendiğinde, sınıf düzeyine göre öğrencilerin fen bilimleri dersi sınıf etkinlilerine yönelik algı puanları ve fen konularına yönelik ilgi puanları arasında istatistiksel olarak anlamlı bir fark olmadığı tespit edilmiştir ( $p>.05)$. Bu sonuca göre, sınıf düzeyleri arasında öğrencilerin fen bilimleri dersi sınıf etkinliklerine yönelik algı ve fen konularına yönelik ilgilerinin benzer olduğu söylenebilir.

Öğrencilerin fen bilimleri dersi sınıf etkinliklerine yönelik algı puanları ile fen konularına yönelik ilgi puanları arasında anlamlı bir ilişkinin varlığına yönelik elde edilen korelasyon analizi sonuçları Tablo 5'te sunulmuştur 
Tablo 5. Fen Bilimleri Dersi Sınıf Etkinliklerim ile Fen Konularına Yönelik İlgi Ölçekleri Puanlarına Ait Korelasyon Analizi Sonuçları

\begin{tabular}{|c|c|c|c|c|c|c|}
\hline Ölçek & Alt Boyut & $\begin{array}{c}\text { Etkinliklere } \\
\text { İlgi }\end{array}$ & $\begin{array}{l}\text { Zevk } \\
\text { Alma }\end{array}$ & $\begin{array}{c}\text { Seçim } \\
\text { Yapabilme }\end{array}$ & $\begin{array}{l}\text { Sinırları } \\
\text { Zorlama }\end{array}$ & $\begin{array}{c}\text { Fen } \\
\text { Konularina } \\
\text { İlgi }\end{array}$ \\
\hline & İlgi Duyma & 1 & & & & \\
\hline Fen Bilimleri Dersi Sinıf & Konudan Zevk Alma & .658 & 1 & & & \\
\hline \multirow{2}{*}{ Etkinliklerim Ölçeği } & Seçim Yapabilme & .448 & .420 & 1 & & \\
\hline & Sinırlarını Zorlama & .663 & .589 & .370 & 1 & \\
\hline Fen Konularına Yönelik İlgi Ölçeği & $\begin{array}{l}\text { Fen konularına yönelik } \\
\text { ilgi }\end{array}$ & $.158^{*}$ & $.208^{*}$ & $.101^{*}$ & $.154^{*}$ & 1 \\
\hline
\end{tabular}

$* \mathrm{p}<.01$

Tablo 5'e göre, Pearson korelasyon analizi sonucunda öğrencilerin fen bilimleri dersi sınıf etkinliklerine yönelik ilgi duyma, etkinliklerden zevk alma, etkinliğin konusuyla ilgili seçim yapabilme, etkinlik sırasında sınırları zorlama puanları ile fen konularına yönelik ilgi puanları arasında pozitif yönde istatistiksel olarak anlamlı bir ilişki olduğu belirlenmiştir $(\mathrm{p}<.01)$. Bu ilişkilerin zayıf düzeyde $(\mathrm{r}=.158 ; \mathrm{r}=.208 ; \mathrm{r}=.101$ ve $\mathrm{r}=.154)$ olduğu görülmektedir.

\section{Sonuç ve Tartışma}

Çalışmada, öğrencilerin cinsiyet ve sınıf değişkenlerine göre fen bilimleri dersi sınıf etkinliklerine ilişkin algıları ile fen konularına yönelik ilgi düzeylerinin belirlenmesi ve aralarındaki ilişkinin açığa çıkartılması amaçlanmıştır.

Çalışma sonuçlarında, öğrencilerin fen bilimleri dersi etkinlikleri algısında etkinliklere yönelik ilgi duyma, etkinlik yapılan konudan zevk alma, seçim yapabilme ve sınırları zorlamaya yönelik puanlarının orta düzeyde olduğu görülmüştür. $\mathrm{Bu}$ sonuç, öğrencilerin fen bilimleri dersi sınıf etkinliklerine yönelik algılarının genel olarak orta düzeyde olduğu şeklinde yorumlanmıştır. Alanyazında öğrencilerin fen bilimleri dersine yönelik genel, tercih yapma, sınırları zorlama, keyifli bulma ve ilgi çekici olma algılarının orta düzeyde olduğu araştırma sonuçları ile bu araştırma sonuçları benzerlik göstermektedir (Gentry, Gable ve Springer, 2000; Gentry vd., 2002; Gentry ve Owen, 2004; Yang vd., 2012). Ancak sınıf etkinliklerinde öğrencilerin seçim yapma algılarının düşük düzeyde olduğu ve öğrencilere yeterince seçim yapma firsatının sunulmadığını orta koyan araştırma sonuçları da alanyazında yer almaktadır (Gentry vd., 2000; Yang vd., 2012). Çalışma sonuçları, öğrencilerin fen bilimleri dersi sınıf etkinliklerine yönelik algılarının beklenilen düzeyde olmadığını ortaya koymaktadır. Bu sebeple öğrencilerin fen bilimleri dersi etkinliklere yönelik olumlu yaklaşımlarını sağlamak için etkinliklerin içeriğinin, uygulanma yöntemlerinin ve ortaya çıarılan ürünlerin ilgi çekici, zevkli, seçim yapabilmeye olanak sağlayan ve sınırları zorlayıcı nitelikte olması önemlidir. Etkinliklere yönelik algının yüksek düzeyde olması öğrencilerin motivasyon ve öğrenmelerini olumlu olarak etkileyecektir (Church vd., 2001; Deniz ve Saranl1, 2017; Kiwanuka vd., 2016; Smyth, 2007). Bu sebeple fen bilimleri dersi sinıf etkinliklerinin düzenlenmesinde eğitimciler öğrencilerin bireysel farklılıklarını dikkate almalı, öğrencinin zihinlerini meşgul edici, rutin uğraşların dışında farklı, eğlenceli ve daha üst düzeyde zihinsel çaba gerektiren etkinlikleri gerçekleştirilmeli, bağımsız çalışmalar ve araştırma projeleri gibi öğrencilerin sınırlarını zorlayıcı uygulamalara yer verilmeli (Clifford, 1990), seçim yapma ve karar alma sürecine öğrenciler dahil edilmelidir (Lepper ve Chabay, 1985; Pintrich ve DeGrot, 1990).

Çalışma sonuçlarında, öğrencilerin fen konularına yönelik ilgi düzeylerinin orta düzeyde olduğu görülmüştür. Ancak alanyazında öğrencilerin fen konularına yönelik ilgi düzeylerinin yüksek olduğu belirtilmektedir (Eke, 2010; Yıldırım ve Köklükaya, 2016). Bu çalışma sonuçları ile alanyazında fen konularına yönelik ilgi düzeyinin yüksek olduğu çalışma sonuçları uyuşmamaktadır. Ayrıca Eder (1992), öğrencilerin biyoloji konularından çok keyif aldıklarını, Erten (2008) insan vücudu, organları, beslenmesi ve sağlığı konularına ilgilerinin yüksek olduğu, Çepni vd., (2006) öğrencilerin dünya, gezegenler ve uzay ve Laçin Şimşek (2007) biyoloji, teknoloji, kimya ve astronomiye yönelik ilgilerinin yüksek olduğu, Hoffmann (2002), öğrencilerin fiziğin günlük uygulamalarına, doğal olayları açıklamadaki potansiyeline ve fizik temelli teknolojilerin kullanımına ilgi duyduklarını belirtmişlerdir. Bu sonuçlarda görüldüğü üzere öğrencilerin biyoloji, sağlık, fiziğin günlük uygulamaları gibi spesifik fen bilimleri konularına yönelik ilgi düzeylerinin yüksek olduğu belirtilmiştir. Sonuç olarak, öğrencilerin belirli fen konularına yönelik ilgileri yüksek iken tüm fen konularına yönelik ilgilerinin daha düşük olduğu düşünülmektedir. Ancak bu çalışma da olduğu gibi öğrencilerin genel fen konularına yönelik ilgi düzeylerinin belirlenmesine yönelik yeterli düzeyde çalışmaya 
alanyazında ulaşılamamıştır. Sonuç olarak öğrencilerin tüm fen konularına yönelik ilgi düzeylerinin belirlenmesine yönelik yeni çalı̧̧malar yapılabilir.

Çalışma sonuçlarında cinsiyet değişkenine göre öğrencilerin fen konularına yönelik ilgi puanları arasında istatistiksel olarak anlamlı bir fark olduğu tespit edilmiştir. Bu sonuç, kız öğrencilerin fen konularına yönelik ilgisinin erkeklerden daha yüksek olduğunu göstermektedir. Alanyazında, Finke (1988), Smail ve Kelly (1984), Löwe (1992) Gehlhaar vd., (1999), Dervişoğlu vd., (2004), Erten (2008) ile Yaman (2009) kız öğrencilerin genel biyoloji, insan vücudu ve organları, beslenme, sağlık, doğa, çevre konuları ve sorunları ve fizik konularına yönelik ilgilerinin erkek öğrencilerden daha fazla olduğu araştırma sonuçları ile bu araştırma sonuçları örtüşmektedir. Ancak alanyazında erkek öğrencilerin fen konularına yönelik ilgi düzeylerinin kızlardan yüksek olduğunu ortaya koyan çalı̧malar da mevcuttur (Yıldırım ve Köklükaya, 2016). Örneğin, erkek öğrencilerin tehlikeli uygulamalara, fiziğge ve teknoloji konularına daha fazla ilgi duydukları belirlenmiştir (Berube, 2000; Holstermann ve Bögeholz, 2007). Bu sonuçlar değerlendirildiğinde, kız öğrencilerin genelde biyoloji, beslenme, sağlık ve çevre konularına yönelik ilgilerinin daha yüksek ve erkek öğrencilerin ise fendeki fizik ve teknoloji konularına daha fazla ilgi duydukları belirlenmiştir. Bu durum, kız öğrencilerin vücutlarına, beslenmesine, sağlığına ve hastalıklara karşı daha hassas olmasından kaynaklanmaktadır. Ayrıca öğrencilerin yaşantıları ile doğrudan ilişki kurabildikleri ve günlük yaşamlarında uygulayabildiği konulara ilgilerinin daha fazla olduğu belirlenmiştir. Fen bilimleri dersi sınıf etkinliklerinin konu tercihinde bu konulara yer verilmesi öğrencilerin ilgisini artırabilir. Ayrıca kız ve erkek öğrenciler arasında oluşabilecek eşitsizliği gidermek için ise fen bilimleri dersi sınıf etkinliklerinde tüm öğrenciler için ilginç gelebilecek konu ve ayrıntılara yer verilmesi, konuların günlük yaşantıyla ilişkilendirilmesi ve etkinliklerde farklı yöntem ve stratejiler kullanması çözüm olabilir. Fen konularında proje çalışmaları, araştırma ödevleri vb. etkinliklere yer verilmesi öğrencileri belirli düzeyde zorlamakla birlikte öğrencilerin ilgilerini ve öğrenmelerini olumlu yönde etkileyebilir. Erkek öğrencilerin bilgisayar destekli fen etkinliklerinde ders konusuna yönelik daha ilgili oldukları belirlenmiştir (Yaman, 2009). Bu durumda fen bilimleri dersi sınıf etkinliklerinde bilgi ve iletişim teknolojileri destekli eğitimler erkek öğrencilerin ilgi duymadığı fen konularına yönelik ilgilerini destekleyebilir.

Araştırma sonuçlarında, kız ve erkek öğrencilerin fen bilimleri dersi sınıf etkinliklerine yönelik algılarının farklılaşmadığ 1 belirlenmiştir. Ancak alanyazında Gentry vd., (2002) ile Aryan ve Shahrokhi (2015) kız öğrencilerin erkeklere göre sınıf etkinliklerini daha ilgi çekici ve keyif verici olarak algıladıklarını ifade etmişlerdir. Bu durumda alanyazındaki araştırma sonuçları ile bu araştırma sonuçları benzerlik göstermemektedir. Bu sonuç, fen bilimleri dersi sınıf etkinliklerine yönelik algı noktasında cinsiyetin etkisini ortaya çıkarıcı daha fazla çalışma yapılabilir.

Araştırma sonuçları, sınıf düzeyine göre öğrencilerin fen bilimleri dersi sınıf etkinliklerine yönelik algılarının ve fen konularına yönelik ilgilerinin farklılaşmadığını ortaya koymaktadır. Alanyazında öğrencilerin sınıf etkinliklerinde ilgi, tercih ve zevk almaya yönelik algılarının sınıf seviyesi arttıkça azaldığını (Gentry vd., 2002; Löwe, 1987) ve ergenlik öncesi dönemde düştügünü ortaya koyan çalışmalar bulunmaktadır (Feldlaufer, Midgley ve Eccles, 1989; Midgley, Anderman ve Hicks, 1995). Ayrıca Gilbert (2006) ile Osbourn ve Collins (2000), öğrencilerin küçük sınıflarda fen konularına daha fazla ilgi gösterdiklerini ve sınıf seviyesi arttıkça ilginin azaldığını belirtmiştir. $\mathrm{Bu}$ araştırma sonuçları ile alanyazın çelişmektedir. Bu sonuç, kullanılan ölçme aracı veya farklı örneklem üzerinde çalışılmış olmasından kaynaklanmış olabilir. Bu nedenle öğrencilerin fen bilimleri dersi etkinliklerine yönelik algılarının sınıf değişkenine göre nasıl değişim gösterdiği ve değişimin sebeplerini derinlemesine irdeleyen daha fazla çalışma yapılabilir.

Araştırma sonuçlarında öğrencilerin fen bilimleri dersi sınıf etkinliklerine yönelik ilgi duyma, etkinliklerden zevk alma, etkinliğin konusuyla ilgili seçim yapabilme, etkinlik sırasında sınırları zorlama puanları ile fen konularına yönelik ilgi puanları arasında pozitif yönde istatistiksel olarak anlamlı bir ilişki olduğu belirlenmiştir. Bu değişkenler arasındaki ilişki zayıf düzeyde de olsa fen bilimleri dersi sınıf etkinlikleri algısının fen konularına yönelik ilgiyi etkilediği söylenilebilir. Ayrıca Palmer (2009) eğitsel içerikli aktivitelerin öğrencilerin ilgi düzeyini artırdığını belirtmiştir. Bu sonuçlara göre, öğrencilerin etkinliğin konusuyla ilgili seçim yapabilme, ilgi duyma, etkinliklerden zevk alma ve sınırları zorlama algıları doğrultusunda fen bilimleri dersi sınıf etkinlikleri düzenlendiğinde öğrencilerin ilgili konulardaki öğrenme isteklerinin artacağı düşünülmektedir. Bu sayede öğrencilerin fen konularına yönelik ilgisi ve başarısı artırılabilir. Çünkü bireyler ilgi duyduğu şeyler hakkında bilgilerini artırmakta ve derinlemesine öğrenmeye sahip olmaktadır (Erten, 2008; Krapp vd., 1992). 
Çalışma sonuçlarında genel olarak bakıldığında öğrencilerin fen bilimleri dersi sınıf etkinlikleri algısı ile fen konularına yönelik ilgi düzeylerinin orta düzeyde olduğu belirlenmiştir. Öğrencilerin fen bilimleri dersi sinıf etkinliklerine yönelik algısı ile fen konularına yönelik ilgileri arasında pozitif yönde istatistiksel olarak anlamlı bir ilişki olduğu tespit edilmiştir. Bu noktada alınyazına katkı olarak fen bilimleri dersi sınıf etkinliklerine yönelik ilgi duyma, etkinliklerden zevk alma, etkinliğin konusuyla ilgili seçim yapabilme, etkinlik sırasında sınırları zorlama noktasındaki algılarının ve konulara yönelik ilginin artırılmasının gerekli olduğu belirlenmiştir. Ayrıca öğrencilerin fen bilimleri dersi sınıf etkinliklerine yönelik algısının geliştirilmesi ile öğrencilerin fen konularına yönelik ilgilerinin artacağı tespit edilmiştir. Bu sebeple fen bilimleri dersi sınıf etkinliklerinde bu özelliklerin geliştirilmesinin gerekli olduğu düşünülmektedir. Bu sonuçlar doğrultusunda şunlar önerilebilir;

Eğitimciler, öğrencilerin fen bilimleri dersi sınıf etkinliklerine yönelik ilgi duyma, etkinlik konularından zevk alma, etkinliğin konusuyla ilgili seçim yapabilme ve etkinlik sırasında sınırlarını zorlamalarına ilişkin algılarını dikkate alarak etkinlikler hazırlayabilirler. Etkinliklerde insan anatomisine, beslenmesine, sağlığına, hastalıklara ve çevre sorunlarına yönelik konulara yer verilebilir. Ayrıca etkinliklerde, öğrencilerin yaşantıları ile doğrudan ilişki kurabildikleri ve günlük yaşamlarında uygulayabildiği konulara yer verilmesi de öğrencilerin fen konularına ilgisini artırabilir. Bilgi ve iletişim teknolojileri destekli fen bilimleri dersi etkinlikleri tasarlanabilir. Bu etkinliklerin tasarlanmasında öğrencilerin zevk alabileceği, farklı ve ilginç konulara, uygun zorluk içeren uygulamalara yer verilmesi ve öğrencilere seçim şansı sunulması bu etkinliklerin niteliğini ve öğrencilerin fen konularına yönelik ilgisini artırabilir.

Araştırma, örneklemi belirleme yöntemi, örneklemin genişliği, kullanılan nicel ölçme araçları sebebiyle sınırlılık göstermektedir. Bu sebeple araştırmacılar, bu çalışmaya benzer şekilde daha geniş örneklemin dâhil edildiği ve nitel veri toplama araçlarının da kullanıldığ 1 yeni çalışmalar gerçekleştirebilirler. 


\section{Extended Summary \\ Introduction}

Factors such as challenging classroom activities, having options about the activities and taking pleasure from the activities can increase the quality of the learning environment during the education process. These factors can also support student motivation and success (Gentry et al., 2002; Yang et al., 2012). Furthermore, quality classroom activities can improve students' interest and enthusiasm (Moore, 2011). It is important to know how students perceive activities during the learning process, because students' perceptions of class activities in terms of attention, enjoyment, opportunity to select and challenge can provide substantial information to the educators and researchers about an effective learning process.

Interest is one of the individual differences which is considered very important by researchers in the field of education (Erten, 2008; Krapp et al., 1992). Lin et al., (2013), Mazer (2013) and Hidi, (2000) stated that the increase in interest of students also increases students' participation in science courses and their motivation for learning. The improvements in classroom activities can positively affect the students' interest in educational subjects (Kang et al., 2010).

It is important to determine students' perceptions of science classroom activities and their interest in science subjects and the relationship between them, because science classroom activities should create curiosity, astonishment and excitement about the subjects (Schiefele and Köller, 2001). Therefore, it is necessary to examine how the classroom activities are perceived by the students, in terms of attention, enjoyment, opportunity to select, and challenge, and whether this has any effect on students' interest in science subjects.

However, it was seen that the studies related to this subject were not sufficient in the literature. Therefore, it is believed that the result of this study will contribute to the literature. In this way, well designed science classroom activities can be developed to encourage students' interest in science subjects, to make them curious, to support their motivation and lead them to success in science subjects.

The aim of the study is to determine the students' perceptions about science classroom activities and their interest in science subjects in terms of gender and class variables and to identify the relationship between them.

\section{Method}

A cross-sectional screening method was used in the study (Büyüköztürk, et al., 2012). The study group included 387 secondary school students from two different schools in 2 different provinces of the Marmara region during the spring term of the 2018-2019 academic year. The study group was determined by the convenience sampling method (Büyüköztürk et al., 2011). $6^{\text {th }}$ to $8^{\text {th }}$ grade students participated in the study. The study data was collected using the Science Classroom Activities Scale and Science Subjects Interest Scale. Descriptive statistics, independent groups ttest and one-way variance (ANOVA) analyses were performed to determine whether students' perceptions about the science classroom activities and their interest towards science subjects showed any statistically significant differences according to gender and grade levels. Correlation analysis was conducted to determine the relationship between the perceptions of science classroom activities and interest in science subjects.

\section{Conclusions and Discussion}

As a result of the study, it was observed that the students' perceptions of science classroom activities in terms of attention, enjoyment, opportunity to select and challenge were at a moderate level. This result is similar to the studies in the literature (Gentry and Owen, 2004). However, there are also other studies in the literature which state that the students' perceptions in selecting classroom activities were at a low level (Gentry et al., 2000).

It was observed that the students' interest levels in the science subjects were at a moderate level. However, in the literature, it is stated that students' levels of interest in science subjects were high (Eke, 2010; Y1ldirım and Köklükaya, 2016). Therefore, the results of this study do not match the results of the studies in the literature. It has been reported that students have high levels of interest in specific science subjects such as human anatomy, health, space and daily applications of physics (Erten, 2008; Laçin Şimşek, 2007). Therefore, further studies should be conducted to determine the interest levels of students in science subjects in general.

The results of this study demonstrated that, according to the gender, there was statistically no significant difference among the interest levels of students in science subjects. In other words, the interest levels of female 
students in science subjects were higher compared to the males. In the literature, Finke (1998), Smail and Kelly (1984), Löwe (1992) Gehlhaar et al., (1999), Dervişoğlu et al., (2004) and Yaman (2009) reported that female students interest in general biology, the human body, nutrition, health, nature and environmental issues was higher than that of the male students. The results of this study are similar to the literature. However, at the same time there are other studies in the literature which state that male students' interest in science subjects was higher than for female students.

In this study, it was determined that, according to gender, there were statistically no significant differences among the perceptions of the students for the class activities in the science courses. However, in the literature, Gentry et al., (2002) and Aryan and Shahrokhi (2015) stated that female students perceived class activities as more interesting and enjoyable than males. In this case, this study and the results of the studies in the literature do not match. Therefore, there is a need for more in depth studies to reveal the effect of gender on the perception of science classroom activities.

In conclusion, it was determined that, according to the grade level, there was statistically no significant difference between the perceptions of the students concerning the science course class activities and their interest levels in science subjects. However, in the literature, there are studies showing that students' perceptions of classroom activities, in terms of attention, preference and pleasure, decreases as the grade level increases (Gentry et al., 2002; Gilbert, 2006; Löwe, 1987). The results of this research contradict the literature. This may be due to the different measurement tools or different sample.

Furthermore, it was determined that there was a positive and statistically significant relationship between students' perceptions of science classroom activities, in terms of attention, enjoyment, opportunity to select and challenge, and students' interest in science subjects.

In the literature, Palmer (2009) stated that educational activities increase the level of students' interest. These results show that if the classroom activities are designed according to the perceptions of students in terms of attention, enjoyment, opportunity to select and challenge, it can increase the students' interest in science subjects. It is suggested that researchers can conduct similar studies with more study groups, using different measurement tools and qualitative data collection methods. 


\section{Kaynakça / References}

Adıgüzel, A. (2009). Sınıf öğretmenlerinin öğrenme etkinliklerini düzenleme ve gerçekleştirme çabalarında zorlanma düzeyleri. Yüzüncü Yll Üniversitesi Ĕ̈itim Fakültesi Dergisi, 6(2). 89-110.

Açıkgöz, K. Ü. (2002). Aktif öğrenme. İzmir: Eğitim Dünyası Yayınları.

Ames, C., \& Archer, J. (1988). Achievement goals in the classroom: Students' learning strategies and motivation processes. Journal of educational psychology, 80(3), 260.

Aryan, E., \& Shahrokhi, M. (2015). Students' perceptions of class activities: An investigation into the role of gender and grade level. Mediterranean Journal of Social Sciences, 6(4), 19-26.

Aypay, A., Çoruk, A., Yazgan, A. D., Kartal, O. Y., Tunçer, B., Attila, S. M., \& Emran, B. (2010). The status of research in educational administration: An analysis of educational administration journals, 1999-2007. Eğitim Araştırmaları Dergisi, 10(39), 59-70.

Berube, C. T. (2000). A Conceptual model for middle school science instruction, The Clearing House, 73(6), 312-315.

Bruning, R. H., Schraw, G. J., \& Norby, M. M. (2014). Bilişsel psikoloji ve ögrretim (Ed. Z. N. Ersözlü \& R. Ülker), Ankara: Nobel Yayıncilik.

Büyüköztürk, Ş., Kılıç, Ç.E., Akgün, Ö.E., Karadeniz, Ş., \& Demirel, F. (2013). Bilimsel Araştırma Yöntemleri (14. baskı). Ankara: PegemA.

Çepni, S., Küçük, M. \& Ayvacı, H. Ş. (2006). Illköğretim 4. sınıf öğrencilerinin fen bilgisi dersine karşı ilgilerinin belirlenmesi. VI. Ulusal Fen Bilimleri ve Matematik Eğitimi Kongresi Bildiriler Kitab1, Cilt I: 258-265.

Church, M. A., Elliot, A. J., \& Gable, S. L. (2001). Perceptions of classroom environment, achievement goals, and achievement outcomes. Journal of Educational Psychology, 93(1), 43.

Clark, B. (2015). Üstün zekalı olarak büyümek. (Translate Eds. F. Kaya and Ü. Ogurlu), Ankara: Nobel Akademik Yayıncılık.

Clifford, M. (1990). Students need challenge, not easy success. Educational Leadership, 48, 22-26.

Deci, E. L. (1995). Why we do what we do: The dynamics of personal autonomy. New York: G. P. Putnam's Sons.

Deniz, K. Z., \& Saranlı, A. G. (2017). Sınıf etkinliklerim ölçeği'nin (SEÖ) Türk kültürüne uyarlanması: Geçerlik ve Güvenirlik Çalışması. Eğitimde ve Psikolojide Ölçme ve Değerlendirme Dergisi, 8(2), 169-182.

Dervişoğlu, S., Yaman, M., \& Soran, H. (2004). Orta öğretim öğrencilerinin biyoloji dersine ve biyoloji konularına ilgilerinin belirlenmesi. Hacettepe Üniversitesi Ĕgitim Fakültesi Dergisi, 27, 67-73.

Doyle, W. (1983). Academic work. Review of Educational Research, 53(2), 159-199.

Eder, F. (1992). Schulklima und entwicklung allgemeiner interessen. (Hrsg. Krapp, A., Prenzel, M.). Interesse, Lernen, Leistung. Münster. Aschendorff 165-194.

Eke, C. (2010). Öğrencilerin fen bilimleri konularına yönelik ilgisi. International Conference on New Trends in Education and Their Implications, 11-13.

Emre, F. E. (2012), İlköğretim öğrencilerinin bitki ve hayvanlara karşı ilgileri ve bu ilgileri belirleyen uyarıcı faktörler (Yayımlanmamış yüksek lisans tezi). Hacettepe Üniversitesi Sosyal Bilimler Enstitüsü, Ankara.

Emre, F.E., \& Erten, S. (2012). İlköğretim öğrencilerinin bitki ve hayvanlara karşı ilgileri ve bu ilgileri belirleyen uyarıcı faktörler. Ulusal Fen Bilimleri ve Matematik Ĕ̈itimi Kongresi, Niğde.

Erten, S. (2008). İlk ve ortaöğretim öğrencilerinin insan biyolojisi konularına yönelik ilgileri. Hacettepe Üniversitesi Eğitim Fakültesi Dergisi, 35, 135-147.

Feldlaufer, H., Midgley, C., \& Eccles, S. (1989). Student, teacher and observer perceptions of the classroom environment before and after the transition to junior high school. Journal of Early Adolescence, 8, 133-156. 
Finke, E. (1998). Interesse an humanbiologie und umweltschutz in der sekundarstufe I. empirische untersuchung zu altersbezogenen veränderungen und anregungsfaktoren. Hamburg: Verlag Dr. Kovač.

Gehlhaar, K.-H., Klepel, G. \& Fankhänel, K. (1999). Analyse der Ontogenese der Interessen an Biologie, insbesondere an Tieren und Pflanzen, an Humanbiologie, Naturund Umweltschutz. (Eds.R. Duit, \& J. Mayer), Studien zur naturwissenschaftlichen Lernund Interessenforschung, Kiel: IPN.

Gentry, M., \& Gable, R. K. (2001). From the students' perspective - My class activities: An instrument for use in research and evaluation. Journal for the Education of the Gifted, 24, 322-343.

Gentry, M., Gable, R. K., \& Rizza M. K. (2002). Students' perceptions of classrooms activities: Are there grade level and gender differences? Journal of Educational Psychology, 94, 539-544.

Gentry, M., Gable, R. K., \& Springer, P. (2000). Gifted and non-gifted middle school students: Are their attitudes toward school different as measured by the new affective instrument, my class activities? Journal for the Education of the Gifted, 24, 7496.

Gentry, M., \& Owen, S. V. (2004). Secondary student perceptions of classroom quality: Instrumentation and differences between advanced/Honors and nonhonors classes. Journal of Secondary Gifted Education, 16(1), 20-29.

George, D. \& Mallery, M. (2010). SPSS for windows step by step: A Simple guide and reference, 17.0 update (10a ed.). Boston: Pearson.

Gilbert, J. K. (2006). On the nature of "Context” in chemical education. International Journal of Science Education, 28( 9), 957976.

Glasser, W. (1996). Then and now. The theory of choice. Learning, 25, 20-22.

Gülbahar ve Aksungur, (2018). Developing the effective classroom communication skills perception scale: Reliability and validity study. Mehmet Akif Ersoy Üniversitesi Eğitim Fakültesi Dergisi, 48, 437-462.

Harty, H. \& Beall, D. (1984). Toward the development of a children's science curiosity measure. Journal of Research in Science Teaching, 21(4), 425-436.

Hidi, S. (2000). Intrinsic and extrinsic motivation: The search for optimal motivation and performance. (Eds, C. Sansone and J. M. Harackiewicz), The search for optimal motivation and performance, San Diego, CA: Academic Press.

Hidi, S, \& Harackiewicz, J. M. (2000). Motivating the academically unmotivated: A critical issue for the 21 st century. Review of Educational Research, 70, 151-179.

Hoffmann, L. (2002). Promoting girls' interest and achievment in physics classes for beginners. Learning and Instruction, 12 (4), 447-465.

Holstermann, N., \& Bögeholz, S. (2007). Interesse von jungen und mädchen an naturwissenschaftlichen themen am ende der sekundarstufe I. Zeitschrift für Didaktik der Naturwissenschaften, 13, 71-86.

Hootstein, E. W. (1994). Motivating middle school students. Middle School Journal, 25(5), 31-35.

Kang, H., Scharmann, L. C., Kang, S., \& Noh, T. (2010). Cognitive conflict and situational interest as factors influencing conceptual change. International Journal of Environmental and Science Education, 5(4), 383-405.

Kiwanuka, H. N., Van Damme, J., Van Den Noortgate, W., Anumendem, D. N., Vanlaar, G., Reynolds, C., \& Namusisi, S. (2016). How do student and classroom characteristics affect attitude toward mathematics? A multivariate multilevel analysis. School Effectiveness and School Improvement, 27, 1-21.

Knogler, M., Harackiewicz, J. M., Gegenfurtner, A., \& Lewalter, D. (2015). How situational is situational interest? Investigating the longitudinal structure of situational interest. Contemporary Educational Psychology, 43, 39-50.

Kopp, K., Mills, S., \& D’Mello, S. K. (2016). Mind wandering during film comprehension: The role of prior knowledge and situational interest. Psychonomic Bulletin \& Review, 23(3), 842-848. 
Krapp, A., Hidi, S., \& Renninger, A. (1992). Interest, learning and development. (Eds, K. A. Renninger, S. Hidi, \& A. Krapp), The role of interest in learning and development, NJ: Erlbaum.

Kök, B. (2012). Üstün zekâlı ve yetenekli öğrencilerde farklılaştırılmış geometri öğretiminin yaratıcılı̆̆a, uzamsal yeteneğe ve başarıya etkisi (Yayımlanmamış doktora tezi). İstanbul Üniversitesi.

Laçin-Şimşek, C. (2007). Öğrenciler fen ve teknoloji dersinde ne öğrenmek istiyorlar. VI. Ulusal Sınıf Öğretmenliği Eğitimi Sempozyumu, Eskişehir.

Laçin Şimşek, C. ve Nuhoğlu, H. (2009). Fen konularına yönelik geçerli ve güvenilir bir ilgi ölçeği geliştirme. Sakarya Üniversitesi Eğitim Fakültesi Dergisi,18, 28-41.

Lepper, M. R., \& Chabay, R. W. (1985). Intrinsic motivation and instruction: Conflicting views on the motivational processes in computer-based education. Educational Psychologist, 20, 217-230.

Lin, S., H., Hong, R. Z., \& Chen, C. Y. (2013). Exploring the development of college students' situational interest in learning science. International Journal of Science Education, 35, 2152-2173.

Löwe, B. (1987). Interessenverfall im Biologieunterricht. Unterricht Biologie, 124, 62-65.

Löwe, B. (1992). Biologieunterricht und Schülerinteresse an Biologie. Weinheim: Deutscher Studien Verlag.

Matthews, M. S., \& McBee, M. T. (2007). School factors and the underachievement of gifted students in a talent search summer program. Gifted Child Quarterly, 51, 167-181.

Mazer, J., P. (2013). Associations among teacher communication behaviors, student interest, and engagement: A validity test. Communication Education, 62, 86-96.

MEB (2013). Ministry of national education, science education program. (Last accessed on 01 July 2018), www.meb.gov.tr

Midgley, C., Anderman, E., \& Hicks, L. (1995). Differences between elementary and middle school teachers and students: A goal theory approach. The Journal of Early Adolescence, 15(1), 90-113.

Moore, D. W. (2011). Direct Instruction: Targeted Strategies For Student Success http://www.insideng.com/profdev/guides/Moore_Instruction.pdf.

Ngoi, M., \& Vondracek, M. (2004). Working with gifted science students in a public high school environment: One school's approach. Prufrock Journal, 15(4), 141-147.

Osborne, J., \& Collins, S. (2000). Pupil's and parents' views of the school science curriculum. School Science Review, 82(298), 23-31.

Özarslan, M., \& Çetin, G. (2018). Gifted and talented students' views about biology activities in a science and art center. Science Education International, 29(1), 49-59.

Palmer, H., D. (2009). Student interest generated during an inquiry skills lesson. Journal of Research in Science Teaching, 46, 147-165.

Pintrich, P. R., \& DeGroot, E. V. (1990). Motivational and self-regulated learning components of classroom academic performance. Journal of Educational Psychology, 82(1), 33-40.

Ravenna, G. (2008). Factors influencing gifted students' preferences for models of teaching (Unpublished dissertation). University of Southern California, Faculty of The Rossier School of Education, California.

Renzulli, J. S. (1994). Schools for talent development: A comprehensive plan for total school improvement. Mansfield Center, CT: Creative Learning.

Rotgans, J. I., \& Schmidt, H. G. (2017). Interest development: Arousing situational interest affects the growth trajectory of individual interest. Contemporary Educational Psychology, 49, 175-184.

Sak, U. (2012). Üstün zekalılar: Özellikleri, tanılanmaları, ĕgitimleri. Ankara: Maya Academy Publishing.

Schiefele, U., \& Köller, O. (2001). Intrinsische und extrinsische motivation. Handwörterbuch Pädagogische Psychologie (Hrsg. D. Rost),. Weinheim: Beltz-PVU. 
Schraw, G., Flowerday, T. \& Lehman, S. (2001). Increasing situational interest in the classroom. Educational Psychology Review, 13(3), 211-224.

Smail, B., \& Kelly, A. (1984). Sex differences in science and technology among 11-year-old school children: II - Affective. Research in Science \& Technological Education, 2(2), 87-106.

Smyth, J. (2007). Toward the pedagogically engaged school: Listen to student voice as a positive response to disengagement and "dropping out"? (Eds. D. Thiessen and A. CookSather), International handbook of student experience in elementary and secondary school, Dordrecht, The Netherlands: Springer.

Şimşek, C. L., \& Nuhoğlu, H. (2009). Fen konularına yönelik geçerli ve güvenilir bir ilgi ölçeği geliştirme. Sakarya Üniversitesi Ĕ̈itim Fakültesi Dergisi, (18), 28-41.

Weber, K., Martin, M., \& Patterson, B. (2010). Teacher behavior, student interest and affective learning: Putting theory to practice. Journal of Applied Communication Research, 29, 71-90.

Yaman, M. (2009). Solunum ve enerji kazanımı konusunda öğrencilerin ilgisini çeken bağlam ve yöntemler. Hacettepe Üniversitesi Ĕgitim Fakültesi Dergisi, 37, 215-228.

Yang, Y., Gentry, M., \& Choi, Y. O. (2012). Gifted students' perceptions of the regular classes and pull-out programs in South Korea. Journal of Advanced Academics, 23(3), 270-287.

Yıldırım, E. G., \& Köklükaya, A. N. (2016). İlk ve ortaokul öğrencilerinin fen konularına yönelik ilgi düzeylerinin belirlenmesi. Amasya Üniversitesi Eğitim Fakültesi Dergisi, 5(1), 1-22. 